\title{
Comparison of different diagnostic tests in dogs uninfected and naturally infected with visceral leishmaniasis
}

Sassaki CY (1), Colodel MM (1), Ferreira I (1), Nogueira FS (2), Lucheis SB (3), Langoni H (4), Rocha NS (1)

(1) Department of Clinical Veterinary Medicine, School of Veterinary Medicine and Animal Husbandry, São Paulo State University (UNESP - Univ Estadual Paulista), Botucatu, São Paulo State, Brazil; (2) School of Veterinary Medicine, Educational Foundation of Andradina (FEA), Andradina, São Paulo State, Brazil, (3) São Paulo Agency of Agribusiness Technology (APTA), Bauru, São Paulo State, Brazil; (4) Department of Veterinary Hygiene and Public Health, School of Veterinary Medicine and Animal Husbandry, São Paulo State University (UNESP - Univ Estadual Paulista), Botucatu, São Paulo State, Brazil.

\begin{abstract}
Uninfected dogs $(n=10)$ and those naturally infected with leishmaniasis $(n=10)$ were subjected to several diagnostic tests, namely: hemoculture, polymerase chain reaction (PCR) of hemoculture, indirect immunofluorescence (RIFI), cytological examination of lymph node aspirate, culture of lymph node aspirate and PCR of lymph node aspirate. RIFI - followed by PCR of lymph node aspirate culture - presented more positive results in infected dogs than in uninfected ones. In infected animals, RIFI was more effective than PCR of lymph node aspirate culture. There was no statistical difference in positivity between RIFI and hemoculture; lymph node aspirate culture/cytological examination of lymph node aspirate and PCR of hemoculture; and between PCR of lymph node aspirate culture and PCR of hemoculture. All infected and uninfected animals had positive and negative results in at least one test. In conclusion, the association of several tests improves the efficacy of canine visceral leishmaniasis diagnosis.
\end{abstract}

Key words: diagnosis, dogs, visceral leishmaniasis.

Visceral leishmaniasis is a chronic infectious disease provoked by the protozoan Leishmania chagasi (in the Americas) and Leshmania infantum (in Europe and Mediterranean regions) that affects the reticuloendothelial system involving the spleen, liver, bone marrow and lymph nodes. Leishmaniasis is found throughout Brazil and has a great impact on public health (1-3).

The presence of a susceptible population, infected reservoirsand abundantvectors constitute the basic requirements for the development of the disease. The Brazilian Program for Visceral Leishmaniasis Surveillance and Control monitors the disease by treating human cases, controlling vectors and euthanizing seropositive infected dogs. Seropositive infected animals are considered to be a source of transmission regardless of the presence of clinical signs $(2,4)$.

Theoretical studies based on mathematical models of transmission of Leishmania infantum infection to humans showed that euthanasia of dogs can be less effective than other control strategies such as the use of insecticides and vaccination (4). Therefore, in order to prevent the infection in dogs and consequently the vector-parasite transmission, and thus reduce the number of cases of human leishmaniasis, in 2003, a canine vaccine for visceral leishmaniasis - Leishmune ${ }^{\varpi}$ produced by Fort Dodge Health Animal Ltd. - came to be commercialized in Brazil (3, 5-8).

In animals immunized with this vaccine and subsequently challenged, both in field and experimental laboratory settings, the induced cellular immune response was demonstrated by flow cytometry, through measurement of CD4, CD8 and CD215,9 and by intradermoreaction (IDR) (6). A study carried out during two years 
demonstrated, by polymerase chain reaction (PCR) of blood and lymph nodes and intradermal reaction, that vaccination provided significant protection against leishmaniasis in 550 dogs from endemic and peri-endemic areas (6). The concomitant reduction of cases of leishmaniasis in dogs and humans in the same district suggested that transmission had halted $(3,7)$.

Serological diagnosis is based on detection of anti-Leishmania antibodies (principally IgG and especially IgG1) and the most widely utilized tests are indirect immunofluorescence (RIFI), ELISA, indirect agglutination and complement fixation which utilize raw antigens. Molecular diagnosis can be accomplished by hybridization tests with specific probes and techniques that amplify nucleic acids, including PCR, to detect DNA, principally in cases of chronic disease, in which the parasites become very scarce as the disease progresses (9-12).

Since there is no data in the literature comparing the results of tests in animals that had been submitted to vaccination against leishmaniasis, the objective of the present study was to compare the results of hemoculture, PCR of hemoculture, RIFI, cytological examination of lymph node aspirate, culture of aspirate lymph node and PCR of lymph node aspirate culture performed in uninfected dogs and in those naturally infected with Leishmania spp., living in endemic areas for canine visceral leishmaniasis.

In the present study, 20 dogs were utilized, without restrictions as to sex, age or breed, from the city of Andradina - located in northwestern São Paulo state, Brazil - an area considered endemic for canine visceral leishmaniasis. Based on serological tests (ELISA), animals were divided into two groups. Group 1 (infected) consisted of ten unvaccinated dogs that were seropositive for leishmaniasis. Group 2 (uninfected) comprised ten dogs serologically negative for leishmaniasis before vaccination; the antibodies were induced by vaccination with Leishmune ${ }^{\circledast}$ produced by the Fort Dodge Health Animal (Campinas, Brazil). The vaccine is composed of the glycoprotein complex fructose-mannose ligand (FML) of Leishmania donovani and the adjuvant saponin. Ninety days after the third dose of vaccine, jugular blood samples and popliteal lymph node aspirates were collected from both groups of dogs.

Part of the lymph node aspirate was ejected onto slides, stained with Giemsa and examined by light microscopy for Leishmania spp. Another fraction of the aspirate was placed in sterile microtubes with $1.5 \mathrm{~mL}$ of sterile buffered saline solution (PBS), $\mathrm{pH} 7.2$, and kept at $-20^{\circ} \mathrm{C}$ until DNA extraction.

The blood samples obtained with EDTA enabled culturing of the leukocyte layer, the sediment of erythrocytes and plasma in liver infusion tryptose (LIT) medium. Aseptic techniques were used. The plasma portion was transferred to culture tubes with cap bakelite containing $5 \mathrm{~mL}$ of sterile LIT medium. This same procedure was repeated for the leukocyte layer and for the erythrocyte sediment. The first hemoculture reading was performed ten days after sample inoculation, removing $30 \mu \mathrm{L}$ from each culture tube and placing it between the slide and coverslip. The reading was accomplished in an optical microscope at 1000x magnification, with immersion oil.

The first subculture was performed 15 to 20 days after sample inoculation, as well as reading of the culture material in an optical microscope at $1000 \mathrm{x}$ magnification. Eight subcultures were completed at 15-day intervals, considering the result negative after the last subculture.

All the cultures, maintained in LIT medium between 28 and $30^{\circ} \mathrm{C}$, were washed in sterile PBS ( $\mathrm{pH} 7.2$ ) and centrifuged at $1,000 \mathrm{rpm}$ for ten minutes, and the sediment stored in labeled sterile microtubes, washed in sterile PBS and kept at $-20^{\circ} \mathrm{C}$ until the moment of DNA extraction for realization of PCR.

Leishmania sp. DNA extraction utilized the kit QIAamp mini kit (S1306, Qiagen, USA), according to the manufacturer's protocol. PCR analysis was performed using the iniciators LINR4 (5' GGGGTTGGTGTAAAATAGGG $3^{\prime}$ ) and LIN19 (5' GAACGCCCCTACCCG 3'), which amplify the conserved region of DNA from the kinetoplast minicircle of the Leishmania (120 bp) genus, according to Ikonomopoulos et al. (11). The amplified products were analyzed in $2 \%$ agarose gel containing $0.5 \mu \mathrm{g} / \mathrm{mL}$ of ethidium bromide (Sigma-Aldrich Co, USA), a molecular weight marker of $100 \mathrm{bp}$ (Invitrogen, USA). An electrophoretic current was applied at 100 volts for 90 minutes. The bands were visualized in an ultraviolet transilluminator, with a $300 \mathrm{~nm}$ filter. The gels were photographed with Polaroid photographic system (Sigma-Aldrich Co, USA). Amplified products of Leishmania major strain 
were utilized as positive controls and TNE as negative controls (Tris-NaCl EDTA).

For RIFI, slides impregnated with Leishmania major antigen were utilized and maintained in tubes containing LIT in an incubator at between 28 and $30^{\circ} \mathrm{C}$ in the Zoonosis Diagnostic Service, UNESP, Botucatu, SP, Brazil. The blood samples were centrifuged at $3,000 \mathrm{rpm}$ for 15 minutes to obtain the serum, which was diluted 1:40 in buffered saline solution, as reaction triage, and promptly tested for IgG antibodies for Leishmania major, as described by Camargo (13). When results were positive, the serum was diluted again until final dilution when florescence was observed. Fluorescent patterns that appeared in 1:40 dilution were considered positive.

Infected dogs were euthanized (sodium thiopental overdose) according to recommendations of the Brazilian Program for Visceral Leishmaniasis Surveillance and Control.

Data were analyzed using Fisher's exact test to calculate statistical significance between Groups 1 e 2 and McNemar's test was employed to calculate statistic significance between groups. A p-value less than 0.05 was considered statistically significant.

The results of laboratory analyses from the 20 dogs are displayed in Table 1. RIFI demonstrated higher positivity in infected dogs than in uninfected animals $(\mathrm{p}=0.0001)$. PCR of lymph node aspirate culture revealed greater diagnostic positivity in infected dogs than in uninfected dogs $(\mathrm{p}=0.003)$. Positivity did not differ statistically between hemoculture and PCR of hemoculture, both in infected and uninfected dogs ( $p>0.05)$.

As uninfected animals had negative results in lymph node aspirate culture and cytological examination of lymph node aspirate, these tests were not statistically compared with infected animals. The positivity of diagnostic tests was compared only in infected animals (Table 2). RIFI revealed more efficient in diagnosingleishmaniasis than PCR of lymph node aspirate culture ( $\mathrm{p}=$ $0.03)$. However, there was no statistical difference $(\mathrm{p}=0.32)$ between positive results of RIFI and sensitivity of hemoculture, lymph node aspirate culture or cytological examination of lymph node aspirate. A similar result was observed when comparing RIFI and PCR of hemoculture ( $\mathrm{p}=$ 0.32) and when comparing PCR of hemoculture and PCR of lymph node aspirate culture $(\mathrm{p}=$ $1.00)$.

In the present study, uninfected animals were not positive in any diagnostic test, except in hemoculture; however, both samples positive by hemoculture were negative by PCR for Leishmania spp. This positivity could be related to Tripanosoma cruzi infection since there are cases of cross-reactions with this parasite and Leishmania spp. $(14,15)$. Nevertheless, this hypothesis was not investigated. The fact that these animals did not present titers in RIFI, which would be the result of vaccine response, may explain why vaccine anti-FML antibodies did not react, or weakly reacted with raw antigen of Leishmania infantum, in the majority of tests.

In the group of infected dogs, one sample was negative by PCR of aspirate lymph node; nevertheless, it was positive in PCR of hemoculture. The other two samples negative by PCR of hemoculture and aspirate lymph node culture were positive by RIFI for Leishmania

Table 1. Comparative result for indirect immunofluorescene reaction (RIFI), hemoculture, polymerase chain reaction (PCR) of hemoculture, and PCR of lymph node aspirate culture in leishmaniasis-infected and uninfected dogs

\begin{tabular}{c|c|c|c|c|c|c|c|c}
\hline \multirow{2}{*}{ Groups } & \multicolumn{2}{|c|}{ RIFI } & \multicolumn{2}{c|}{ Hemoculture } & \multicolumn{2}{c|}{ PCR of hemoculture } & \multicolumn{2}{c}{$\begin{array}{c}\text { PCR of lymph node } \\
\text { aspirate culture }\end{array}$} \\
\cline { 2 - 10 } & Positive & Negative & Positive & Negative & Positive & Negative & Positive & Negative \\
\hline Infected & 9 & 1 & 0 & 10 & 3 & 7 & 7 & 3 \\
\hline Uninfected & 0 & 10 & 2 & 8 & 0 & 10 & 0 & 10 \\
\hline Total & 9 & 11 & 2 & 18 & 3 & 17 & 7 & 13 \\
\hline$p$ & \multicolumn{3}{|c|}{0.0001} & \multicolumn{2}{c|}{0.24} & & 0.21 & \multicolumn{2}{c}{0.003} \\
\hline
\end{tabular}

Fisher's exact test. 
Table 2. Comparison of diagnostic tests in animals infected with Leishmania sp.

\begin{tabular}{c|c|c|c|c|c|c|c}
\hline & RIFI & Hemoculture & $\begin{array}{c}\text { Lymph } \\
\text { node } \\
\text { aspirate } \\
\text { culture }\end{array}$ & $\begin{array}{c}\text { Cytological } \\
\text { examination } \\
\text { of lymph node } \\
\text { aspirate }\end{array}$ & $\begin{array}{c}\text { PCR of } \\
\text { hemoculture }\end{array}$ & $\begin{array}{c}\text { PCR of } \\
\text { aspirate } \\
\text { lymph } \\
\text { node } \\
\text { culture }\end{array}$ & $\begin{array}{c}\text { Total } \\
\text { Positive }\end{array}$ \\
\hline Negative & 1 & 0 & 0 & 0 & 3 & 7 & 3 \\
\hline Total & 10 & 10 & 10 & 10 & 10 & 10 & 61 \\
\hline
\end{tabular}

RIFI vs. hemoculture $=$ aspirate lymph node culture $=$ cytological examination of lymph node aspirate: $p=0.32$

RIFI vs. PCR of hemoculture: $p=0.32$

RIFI vs. PCR of lymph node aspirate culture: $p=0.03$

PCR of hemoculture vs. PCR of lymph node aspirate culture: $p=1.00$

McNemar's test was utilized in comparisons.

spp. Among these animals, the highest positivity was shown by RIFI (90\%), followed by PCR of lymph node aspirate culture (70\%) and PCR of hemoculture $(30 \%)$. These results are similar to those found by Ikonomopoulos et al. (11), Langoni et al. (16) and Silva et al. (17), who compared RIFI with PCR and also observed that RIFI was more sensitive. In addition, analogous results were obtained by Reale et al. (12), who found that PCR of aspirate lymph node presented higher positivity than PCR of blood. Nevertheless, they differ from results obtained by de Andrade et al. (10), who concluded that PCR was more sensitive that RIFI, showing that there are differences in results when comparing diagnostic tests.

In conclusion, different tests can be utilized to diagnose canine visceral leishmaniasis. However, in the present study, it was observed that all infected animals had positive results in at least one test, but not in all, whereas all uninfected animals tested negative by at least one technique, but not by all, which suggests the association of several tests to improve diagnostic efficacy for the final decision as to the destiny of affected animals.

\section{ACKNOWLEDGEMENTS}

The authors are grateful to The State of São Paulo Research Foundation (FAPESP) for the scholarship (process 2005/56765-9) and Fort Dodge Animal Health for the financial support.

\section{COPYRIGHT}

(c) CEVAP 2011

\section{SUBMISSION STATUS}

Received: February 23, 2011.

Accepted: June 7, 2011.

Abstract published online: June 17, 2011.

Full paper published online: August 31, 2011.

\section{CONFLICTS OF INTEREST}

There is no conflict.

\section{FINANCIAL SOURCE}

The State of São Paulo Research Foundation (FAPESP) and Fort Dodge Animal Health provided the financial grants.

\section{ETHICS COMMITTEE APPROVAL}

The present study was approved by the Ethics Committee on Animal Experimentation of the School of Veterinary Medicine and Animal Husbandry (CEEA - process number 58/2005), UNESP, Botucatu, SP, Brazil.

\section{CORRESPONDENCE TO}

ISABELLE FERREIRA, Faculdade de Medicina Veterinária e Zootecnia, UNESP, Distrito de Rubião Júnior, s/n, Botucatu, SP, 18618-000, Brasil. Phone: +55 143811 6293. Email: iferreira@ fmvz.unesp.br.

\section{REFERENCES}

1. Bavia ME, Carneiro DD, Gurgel Hda C, Madureira Filho C, Barbosa MG. Remote sensing and geographic information systems and risk of American visceral leishmaniasis in Bahia, Brazil. Parassitologia. 2005;47(1):165-9.

2. Barbiéri CL. Immunology of canine leishmaniasis. 
Parasite Immunol. 2006;28(7):329-37.

3. Palatnik-de-Sousa CB, Silvia-Antunes I, Morgado AA, Menz I, Palatnik M, Lavor C. Decrease of the incidence of human and canine visceral leishmaniasis after dog vaccination with Leishmune ${ }^{\varpi}$ in Brazilian endemic areas. Vaccine. 2009;27(27):3505-12.

4. Dye C. The logic of visceral leishmaniasis control. Am J Trop Med Hyg 1996; 55(2):125-30.

5. Araújo MS, de Andrade RA, Vianna LR, Mayrink W, Reis AB, Sathler-Avelar R, et al. Despite Leishvaccine and Leishmune trigger distinct immune profiles, their ability to activate phagocytes and CD8+ T-cells support their high quality immunogenic potential against canine visceral leishmaniasis. Vaccine. 2008;26(18):2211-24.

6. Borja-Cabrera GP, Santos FN, Bauer FS, Parra LE, Menz I, Morgado AA, et al. Immunogenicity assay of the Leishmune ${ }^{\oplus}$ vaccine against canine visceral leishmaniasis in Brazil. Vaccine. 2008;26(39):4991-7.

7. Fort Dodge Saúde Animal [Internet]. Leishmune: vacina contra leishmaniose visceral canina. [Cited 2009 June 19]. Available from: http://www.leishmune.com. br/leishmaniose/Leishmune/Outros/Diversos/14682_ folheto.pdf.

8. Nogueira FS, Moreira MAB, Borja-Cabrera GP, Santos FN, Menz I, Parra LE, et al. Leishmune ${ }^{\circledast}$ vaccine blocks the transmission of canine visceral leishmaniasis: absence of Leishmania parasites in blood, skin and lymph nodes of vaccinated exposed dogs. Vaccine. 2005;23(40):4805-10.

9. Andrade RA, Reis AB, Gontijo CMF, Braga LB, Rocha $\mathrm{RD}$, Araújo MS, et al. Clinical value of anti-Leishmania (Leishmania) chagasi IgG titers detected by flow cytometry to distinguish infected from vacinated dogs. Vet Immunol Immunopathol. 2007;116(1-2):85-97.

10. de Andrade HM, Reis AB, dos Santos SL, Volpini AC, Marques MJ, Romanha AJ. Use of PCR-RFLP to identify Leishmania species in naturally-infected dogs. Vet Parasitol. 2006;140(3-4):231-8.
11. Ikonomopoulos J, Kokotas S, Gazouli M, Zavras A, Stoitsiou M, Gorgoulis VG. Molecular diagnosis of leishmaniasis in dogs: comparative application of traditional diagnostic methods and the proposed assay on clinical samples. Vet Parasitol. 2003;113(2):99-113.

12. Reale S, Maxia L, Vitale F, Glorioso NS, Caracappa S, Vesco G. Detection of Leishmania infantum in dogs by PCR with lymph node aspirates and blood. J Clin Microbiol. 1999;37(9):2931-5.

13. Camargo ME. Fluorescent antibody test for the serodiagnosis of American trypanosomiasis: technical modification employing preserved culture forms of Trypanossoma cruzi in a slide test. Rev Inst Med Trop. 1966;8(5):227-34.

14. Luciano RM, Lucheis SB, Trocarelli MZ, Luciano DM, Langoni H. Avaliação da reatividade cruzada entre antígenos de Leishmania spp. e Trypanosoma cruzi na resposta sorológica de cães pela técnica de imunofluorescência indireta (RIFI). Braz J Vet Res An Sci. 2009;46(3):181-7.

15. Madeira MF, Sousa MA, Barros JH, Figueiredo FB, Fagundes A, Schubach A. Trypanosoma caninum n. sp. (Protozoa: Kinetoplastida) isolated from intact skin of a domestic dog (Canis familiaris) captured in Rio de Janeiro, Brazil. Parasitology. 2009;136(4):41123.

16. Langoni H, Lucheis SB, Silva RC, Castro AP, Paes AC. American visceral leishmaniasis: a case report. J Venom Anim Toxins incl Trop Dis. 2005;11(3):360-71.

17. Silva DA, Madeira MF, Teixeira AC, de Souza CM, Figueiredo FB. Laboratory tests performed on Leishmania seroreactive dogs euthanized by the leishmaniasis control program. Vet Parasitol. 2011;179(1-3):257-61. 